\title{
Total Clearance Predicted Normalized by Weight
}

National Cancer Institute

\section{Source}

National Cancer Institute. Total Clearance Predicted Normalized by Weight. NCI

Thesaurus. Code C92424.

The predicted total body clearance for intravascular administration divided by the weight. 